\title{
How Strange the Words Sound after She's Gone · Jim Gaver
}

To be perfectly honest I awoke this morning thinking About cows, about the word cows, a thought that it seems Was already hungry, though at the same time content To follow itself around in a neat little pasture For most of the morning, contemplating the grass On a non-existent hill.

Or maybe I awoke with a new way of thinking About elm trees, that's what it was, I remember the thought Seemed to think it could feel its own shadow Growing thinner, it already seemed to feel it was The shadow of what it was.

I awoke this morning beyond a doubt in the shadow Of what was, and to be candid about it began to consider How narrow the road is, my fast-moving thought about prepositions That stands watching its own path curve away going over a hilltop, leaving me Where we were, in a strange rolling countryside That has lost all capacity to think Its way out.

Frankly, until this morning, I had not seen Cows and elm trees get lost here, wandering stupidly In my words for them until they wound up In my words for them, with no way out. Until this morning, when she left me, I had never seen How empty our house looks as the words for a thought That left me, a thought that left behind it Only the perfect words for it, as empty as these rooms. This morning, in fact, I woke up empty, with just the words She left me, with just those words, and a thought

About vacant houses that seemed to see

Only its own reflection as it stood in the yard

With the last of the elm trees, hoping for one last look Through the window of its words.

What I am trying to say is that I awoke this morning Trying as strange as it sounds to say How strange the words sound as I try

To say them, as I try to say 
How strange the words sound and that's just

What I say. So many empty words!

This morning I woke up in one room of a house filled

With words, filled with the word words, my small vocabulary

In a strange new language, a language that is itself

A large empty house to which, in all honesty,

I am slowly adding rooms. 